BMJ Open

Diabetes

Research

\& Care

\section{Egg ingestion in adults with type 2 diabetes: effects on glycemic control, anthropometry, and diet quality - a randomized, controlled, crossover trial}

To cite: Njike VY, Ayettey RG, Rajebi $\mathrm{H}$, et al. Egg ingestion in adults with type 2 diabetes: effects on glycemic control, anthropometry, and diet quality - a randomized, controlled, crossover trial. BMJ Open Diabetes Research and Care 2016:4:e000281. doi:10.1136/bmjdrc-2016000281

Received 2 June 2016 Revised 5 October 2016 Accepted 9 October 2016

\section{CrossMark}

\footnotetext{
${ }^{1}$ Yale University Prevention Research Center, Derby, Connecticut, USA ${ }^{2}$ Griffin Hospital, Derby, Connecticut, USA
}

Correspondence to Dr David L Katz; davkatz7@gmail.com

\section{ABSTRACT}

Background: The inclusion of eggs as part of a healthful diet for adults with diabetes is controversial. We examined the effects of including eggs in the diet of adults with type 2 diabetes on cardiometabolic risk factors.

Methods: Randomized, controlled, single-blind, crossover trial of 34 adults (mean age 64.5 years; 14 postmenopausal women, 20 men) with type 2 diabetes assigned to one of two possible sequence permutations of two different 12-week treatments (two eggs/day inclusion or egg exclusion), with 6-week washout periods. For the egg inclusion phase, participants received advice from a dietitian on how to preserve an isocaloric condition relative to the egg exclusion phase. The primary outcome was glycemic control as measured by glycated hemoglobin.

Secondary measures included anthropometry, blood pressure, and diet quality.

Results: Compared with the exclusion of eggs in the habitual diet, the inclusion of eggs did not measurably affect glycated hemoglobin $(0.01 \pm 0.5 \%$ vs -0.24 $\pm 0.7 \% ; p=0.115)$ and systolic blood pressure $(-0.8$ \pm 13.0 vs $-3.0 \pm 10.0 \mathrm{~mm} \mathrm{Hg} ; p=0.438$ ); and significantly reduced body mass index $(0.06 \pm 0.8$ vs $\left.-0.4 \pm 0.8 \mathrm{~kg} / \mathrm{m}^{2} ; \mathrm{p}=0.013\right)$ and visceral fat rating $(0.2$ \pm 1.1 vs $-0.4 \pm 1.0 ; p=0.016$ ). The inclusion of eggs in the habitual diet of diabetics significantly reduced waist circumference $(-0.4 \pm 1.2 \mathrm{~cm} ; p=0.004)$ and percent body fat $(-0.7 \pm 1.8 ; p=0.033)$ from baseline.

Conclusions: Short-term daily inclusion of eggs in the habitual diet of adults with type 2 diabetes does not improve glycemic control but can improve anthropometric measures.

Trial registration number: NCT02052037; results.

\section{INTRODUCTION}

Diabetes is a public health problem of epidemic proportions. According to recent estimates, $12.3 \%$ of US adults aged 20 years and older, and $25.9 \%$ of those aged 65 years and older, have diabetes. In addition, another $37 \%$ of US adults aged 20 years or older, and $51 \%$ of those aged 65 years or older, have

\section{Key messages}

- Daily inclusion of eggs in the diets of type 2 diabetics may lead to reduced body weight.

- Daily inclusion of eggs in the diets of type 2 diabetics may lead to reduced visceral fat rating.

- Daily inclusion of eggs in the diets of type 2 diabetics may lead to reduced waist circumference.

prediabetes. Type 2 diabetes accounts for about $90-95 \%$ of all diagnosed cases. ${ }^{1}$

Diabetes is the seventh leading cause of death in the USA. Diabetes complications include cardiovascular disease, stroke, hypertension, blindness, kidney disease, nervous system damage, limb amputations, and biochemical imbalances that can cause acute life-threatening events. Rates of cardiovascular mortality are about 1.7 times higher among adults aged 18 years or older with diagnosed diabetes than among adults without diagnosed diabetes. ${ }^{1}$

Overweight or obesity is a primary risk factor for type 2 diabetes. ${ }^{2}$ Compared with healthy weight adults, obese individuals are more than seven times more likely to develop type 2 diabetes. ${ }^{3}$ The more fatty tissue that is present in the body, the more resistant the cells become to insulin. ${ }^{4}$ Fat stored primarily in the abdomen increases the risk of type 2 diabetes greater than if the fat were stored elsewhere, such as in the hips and thighs. ${ }^{4}$ Weight gain of as little as $10 \mathrm{lb}$ over 15 years can double a person's insulin resistance and increase the risk of diabetes. ${ }^{4}$ Insulin resistance may also contribute to high blood pressure, increased triglycerides and low-density lipoprotein (LDL) cholesterol, and reduced levels of high-density lipoprotein (HDL) cholesterol. ${ }^{5}$

Weight reduction is an important objective for overweight or obese individuals with type 2 diabetes. ${ }^{6}$ A moderate and sustained 
weight reduction of $5-7 \%$ of body weight can improve insulin sensitivity, decrease fasting glucose, and reduce the need for some diabetes medications. ${ }^{2}{ }^{7-13}$ Healthful eating is the cornerstone management approach for blood glucose control in diabetes by controlling body weight. ${ }^{1}$ Another important goal of type 2 diabetes management is the reduction of cardiovascular disease risk factors such as high blood pressure. ${ }^{1}$

Foods such as plant-based protein sources, for example, beans, nuts, seeds, or tofu; fish and seafood; chicken and other poultry; and low-fat dairy products with a low glycemic index are typically recommended to control blood glucose in diabetes. ${ }^{8}$ However, the inclusion of eggs in a healthful diabetic diet has been controversial. In a meta-analysis by Shin $e t a l,{ }^{14}$ egg consumption was associated with an increased incidence of type 2 diabetes in the general population and cardiovascular morbidity among diabetes patients. In another recent meta-analysis by Djoussé et al, ${ }^{15}$ infrequent egg consumption showed no association with type 2 diabetes, but consumption of three or more eggs per week demonstrated a modest increase in the risk of type 2 diabetes. In another recent meta-analysis by Tamez et $a l^{16}$ studies conducted in the USA had a strong association between egg consumption and the incidence of type 2 diabetes, while studies conducted elsewhere showed no association. As a satiating and protein-rich food, eggs seem to have potential to foster calorie and weight control, and to reduce the dietary glycemic load, offering potential advantages in type 2 diabetes. We conducted a prospective, randomized, single-blind, controlled, crossover trial to assess the effects of daily egg inclusion (ie, 2 eggs per day) in the habitual diet for a 3-month period in comparison to egg exclusion on glycemic control, anthropometric measures, and overall diet quality in adults with type 2 diabetes.

\section{METHODS}

\section{Study population}

A cohort of 34 participants (20 men and 14 women) was recruited from the Lower Naugatuck Valley in Connecticut through flyers and newspaper advertisements. Interested participants $(n=351)$ were prescreened over the telephone. The study coordinator/research assistant prescreened potential participants for eligibility via a structured telephone interview using established inclusion criteria. Those who met preliminary eligibility criteria and agreed to participate were invited to undergo clinical eligibility screening, and asked to sign a consent form approved by the Griffin Hospital Institutional Review Board. All participants were informed of the option of discontinuing participation at any time during the study. They were advised to discontinue egg intake at least 4 weeks before receiving the intervention. The clinical screening physical examination consisted of weight, height, and blood pressure measures obtained by experienced study personnel using calibrated equipment. Participants underwent a glycated hemoglobin (HbAlc) assessment. All screening laboratory assays were performed at the Griffin Hospital clinical laboratories. Participant eligibility was determined based on the clinical screening results. Subject participation and flow through the trial are shown in figure 1 .

Inclusion criteria: (1) men greater than 35 years of age; (2) postmenopausal women not currently on hormone replacement therapy; (3) non-smokers; (4) clinical diagnosis of type 2 diabetes mellitus for at least 1 year but no more than 5 years; (5) $6.5 \% \leq \mathrm{HbAlc} \leq 8.0 \%$; (6) body mass index (BMI) between 25 and $40 \mathrm{~kg} / \mathrm{m}^{2}$.

Exclusion criteria: (1) failure to meet inclusion criteria; (2) anticipated inability to complete the study protocol for any reason; (3) current eating disorder; (4) use of antihyperglycemic, lipid-lowering or antihypertensive medications unless stable on medication for at least 3 months; (5) use of glucocorticoids, antineoplastic agents, psychoactive agents, or nutraceuticals; (6) regular use of fiber supplements; (7) restricted diets (ie, vegetarian, vegan, gluten free); (8) known allergy to eggs.

\section{Study design}

This was a randomized, single-blind, crossover trial designed with a 4-week run-in period and two treatment assignments to compare the effects of 12 weeks of daily inclusion or daily exclusion of eggs on glycemic control in adults with type 2 diabetes. After a 4-week run-period of an ad libitum diet, participants were randomized to one of two possible sequence permutations, and then underwent repeated measures following inclusion of 10-14 eggs/week or egg exclusion for 3 months in their diet in random sequence, with a 6 -week washout between treatments. To provide a sound basis for the statistical comparison of outcome measures for treatment assignments, participants were randomized to one of two sequence permutations of egg inclusion and egg exclusion from the habitual diet. Each permutation included a 12-week treatment phase, followed by a 6-week washout phase, followed by 12-week treatment phase (36 weeks total for each study participant).

\section{Intervention \\ Egg inclusion phase}

Participants met with a registered dietitian and received instructions for including two eggs per day (10-14 eggs/ week) as part of their otherwise habitual ad libitum diet, while preserving an isocaloric condition relative to the egg exclusion phase. The study dietitian provided individualized guidance to participants on how to make room calorically for two daily eggs in their diet, relative to their habitual intake during the egg exclusion phase, while giving them latitude in determining how to adjust for the approximately $150-300$ extra daily calories from the eggs, to better approximate real-world conditions. The participants were instructed to make approximate 


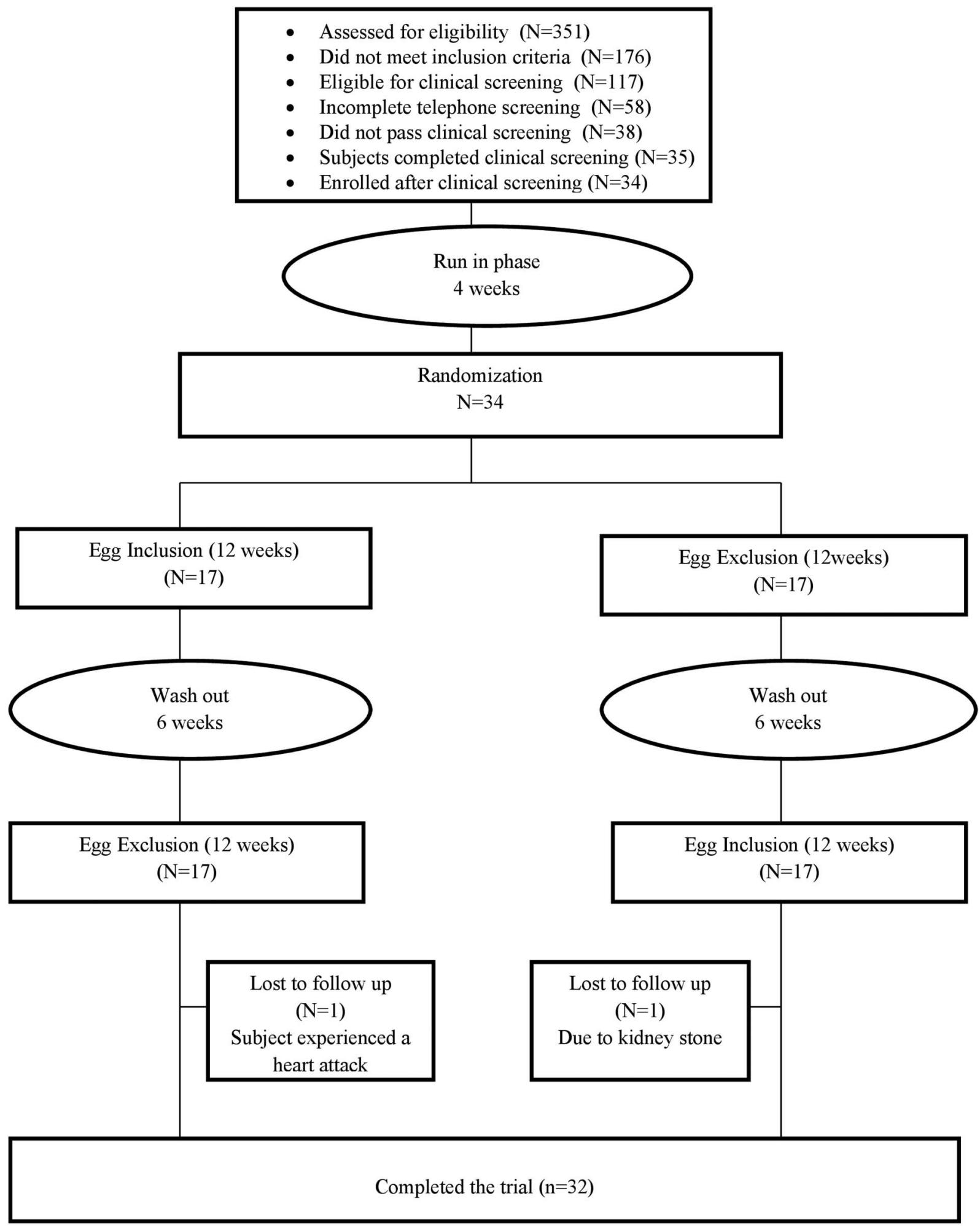

Figure 1 Study flow diagram.

caloric adjustments for the eggs depending on their preferred method of preparation, for example, hard-boiled, poached, fried, scrambled, or as part of egg salad or an omelet on a given day. All eggs for this study phase were provided to participants by the researchers. The eggs were acquired from the Griffin Hospital Dining Services department, which in turn ordered the eggs from one of its vendors.

\section{Egg exclusion phase}

Participants met with the dietitian and received relevant meal planning guidance and instructions to follow their 
usual ad libitum diets, with the exception of avoiding eggs and specific egg-containing products.

During both intervention phases, study participants were advised to eat to their usual state of fullness, and their weight and dietary intake were monitored to ensure that an isocaloric condition was maintained.

\section{Outcome measures}

Outcome measurements were evaluated at baseline, after a run-in period with an ad libitum diet, and then after each of the two interventions (ie, egg inclusion and egg exclusion). During each visit to the Prevention Research Center (PRC), subjects underwent measures of HbAlc, fasting plasma glucose, and fasting plasma insulin, along with an assessment of anthropometric values, and completed a 3-day food record. Physical activity level and prescription medication use were assessed at the end of each phase to monitor variation of activity level and medication intake. A written side effects survey was completed once at the end of each phase.

\section{Primary outcome measures}

Glycemic control: HbA1c was used to measure the average plasma glucose concentration. The HbAlc is a predictor of the average amount of plasma glucose. It serves as a marker for average blood glucose levels over the previous 3 months before the measurement, as this is the lifespan of red blood cells. In diabetics, higher amounts of HbAlc indicate poor control of blood glucose levels. HbAlc was measured using a finger-prick test.

\section{Secondary outcome measures}

Fasting glucose and insulin: Glucose and insulin were measured at each time point. Participants were asked to fast for at least 8 hours before glucose and insulin measurement. Homeostasis Model Assessment (HOMA-IR) values were calculated from fasting serum glucose and serum insulin levels using HOMA calculator V.2.2.1 to gauge the degree of insulin resistance.

Body composition: Body composition was measured using bioelectrical impedance analysis (BIA), which uses the resistance of electrical flow through the body to estimate body fat. The Tanita SC-240 Body Composition Analyzer was used to measure body composition. The SC-240 Body Composition Analyzer measures weight and calculates body fat percentage and total body water percentage, in addition to BMI. In a multicenter European study by Deurenberg et $a l,{ }^{17}$ with adults between the ages of 18 and 70 years, the use of an impedance-based prediction equation for body fat percentage (which is the basis for the Tanita SC-240 Body Composition Analyzer function) when compared with either dual-energy X-ray absorptiometry (DXA) or densitometry (underwater weighing) - two current standards used to measure body composition-was found to provide good estimates of body fat percentage. In addition, the Tanita SC-240 Body Composition Analyzer has demonstrated accuracy in estimating body fat percentage as compared with DXA in white and African-American children and adolescents. ${ }^{18}$ Studies have shown correlation in visceral fat rating between BIA and abdominal radiographic imaging exams. ${ }^{19-21}$

Body weight: Body weight was measured during each visit. It was measured to the nearest $0.5 \mathrm{lb}$ using a balancetype medical scale. Subjects were measured in the morning (fasting), unclothed with the exception of undergarments.

Waist circumference: Waist circumference was measured using the US government standard protocol. It was measured around the narrowest point between ribs and hips when viewed from the front after exhaling.

Diet quality: To help the study team track any variation in dietary pattern over the course of the study, all participants were asked at two time points to provide information on the foods and beverages that they consumed. Three 24-hour recalls (ie, for two weekdays and one weekend day) were collected at each time point. For each 3-day period, participants completed three 24-hour recalls using a web-based Automated Self-Administered 24-Hour Recall (ASA24) (available from the National Cancer Institute at http://riskfactor.cancer.gov/tools/ instruments/asa24/) which guided them through the process of completing the recall data. Diet quality based on these recalls (ie, the average of the 3-day recalls at each time point of assessment) was assessed using the Healthy Eating Index 2010.

Medication use: We tracked any changes in prescription medication use. We controlled for this variable in our multivariable regression models.

Compliance: During each visit to the PRC, the study coordinator/research assistant met with participants to answer questions, document any study-related health or other issues, and assess compliance to the treatment assignment. Compliance was assessed by self-report, using egg consumption logs returned by participants at the end of each phase. Good compliance was defined as $>80 \%$ use of treatment. Habitual dietary pattern, as assessed by the average of three 24-hour recalls during each phase, was also used to monitor compliance. Variation in compliance was used as a control variable in multivariable analysis; intertreatment comparisons were conducted in accord with the intention-to-treat principle.

\section{Statistical analysis}

Generalized linear models were used to analyze changes in our outcome measures between treatment assignments. Changes in outcome measures from baseline were assessed using paired t-test. Regression models were used to adjust for potential confounding factors (ie, age, gender, race, medication use, compliance, and treatment sequence). To preserve randomization, all analyses of end points were based on the intention-to-treat principle. Results are expressed as means \pm SD in text and tables except otherwise stated. SAS software for Windows 
V.9.3 (SAS Institute, Cary, North Carolina, USA) was used to carry out all statistical analyses.

The sample size was estimated to provide $\geq 80 \%$ power to detect a minimal difference of $-0.3 \%$ in HbAlc between egg inclusion and egg exclusion in the habitual diet, with maximum allowable type I error of $5 \%$. An SD of $0.6 \%$ in $\mathrm{HbA1c}$ was used to compute the sample size. $^{22}$

\section{Study participants}

A total of 34 adults with type 2 diabetes enrolled in the study. Of these, 32 completed the study. One participant withdrew for a health reason (ie, a kidney stone) unrelated to the study intervention during the egg inclusion phase, and another dropped out due to a myocardial infarction during the egg exclusion phase. Most of the study participants were men $(58.8 \%)$, predominantly Caucasians $(76.5 \%)$ with a mean age of 64.5 years. Almost all the study participants $(97.1 \%)$ were taking diabetes medications; most of the participants $(82.4 \%)$ were on lipid-lowering medications; and nearly three-quarters of the participants $(70.6 \%)$ were on blood pressure-lowering medications. Baseline clinical outcome measures (ie, HbA1c, insulin resistance, anthropometric measures, and blood pressure) were comparable $(\mathrm{p}>0.05)$ during the egg exclusion phase as compared with the egg inclusion phase. Detailed information about participants' demographic characteristics and medication use are presented in table 1.

\section{Efficacy end point}

Daily inclusion of two eggs for 12 weeks in the habitual diet of study participants non-significantly reduced HbA1c $\quad(-0.24 \pm 0.7 \% \quad$ vs $\quad 0.01 \pm 0.5 \% ; \quad \mathrm{p}=0.115) \quad$ as

Table 1 Demographic characteristics and medication use of study participants

\begin{tabular}{|c|c|}
\hline Variable & Value $(n=34)$ \\
\hline \multicolumn{2}{|l|}{ Gender } \\
\hline Female & $14(41.2 \%)$ \\
\hline Male & $20(58.8 \%)$ \\
\hline \multicolumn{2}{|l|}{ Race } \\
\hline White or Caucasian & $26(76.5 \%)$ \\
\hline Black or African-American & $3(8.8 \%)$ \\
\hline Hispanic & $5(14.7 \%)$ \\
\hline $\mathrm{Age}^{\star}$ (years) & $64.5 \pm 7.6$ \\
\hline Diabetes medication use $†$ & $33(97.1 \%)$ \\
\hline Lipid-lowering medication useł & $28(82.4 \%)$ \\
\hline Blood pressure medication use & $24(70.6 \%)$ \\
\hline \multicolumn{2}{|c|}{$\begin{array}{l}\text { *Values are mean } \pm \text { SD. } \\
\text { †Medications included metformin, pioglitazone, glipizide, } \\
\text { gliclazide, glyburide, glimepiride, sitagliptin, linagliptin, } \\
\text { canagliflozin, saxagliptin, insulin, and insulin glargine. } \\
\text { †Medications included simvastatin, atorvastatin, lovastatin, } \\
\text { fenofibrate, omega-3-acid ethyl esters, and rosuvastatin. } \\
\text { §Medications included metoprolol, atenolol, nebivolol, carvedilol, } \\
\text { lisinopril, valsartan, quinapril, ramipril, losartan, amlodipine, } \\
\text { hydrochlorothiazide, and teralosin. }\end{array}$} \\
\hline
\end{tabular}

compared with egg exclusion of the study participants. The inclusion of eggs in the habitual diet nonsignificantly reduced $\mathrm{HbA1c}$ from baseline $(-0.24 \pm 0.7 \%$; $\mathrm{p}=0.062$ ). Daily inclusion of eggs, as compared with the exclusion of eggs from the habitual diet, did not improve insulin resistance (HOMA: $0.3 \pm 6.9$ vs $1.5 \pm 4.1$; $\mathrm{p}=0.420$ ). However, the exclusion of eggs from the habitual diet significantly increased insulin resistance from baseline (HOMA: $1.5 \pm 4.1 ; \mathrm{p}=0.047$ ).

Daily inclusion of eggs in the habitual diet, as compared with the exclusion of eggs, did not lower diastolic blood pressure $(-0.5 \pm 6.1$ vs $0.9 \pm 9.1 \mathrm{~mm} \mathrm{Hg} ; \mathrm{p}=0.460)$. Similarly, daily inclusion of eggs in the habitual diet, as compared with egg exclusion, did not lower systolic blood pressure $(-3.0 \pm 10.0$ vs $-0.8 \pm 13.0 \mathrm{~mm} \mathrm{Hg}$; $\mathrm{p}=0.438$ ). However, daily inclusion of eggs in the habitual diet marginally significantly reduced systolic blood pressure from baseline $(-3.0 \pm 10.0 \mathrm{~mm} \mathrm{Hg} ; \mathrm{p}=0.091)$.

Daily inclusion of eggs in the habitual diet, as compared with the exclusion of eggs, significantly reduced body weight (weight: $-2.9 \pm 5.0$ vs $-0.8 \pm 13.0 \mathrm{lb} ; \mathrm{p}=0.007$, BMI: $-0.4 \pm 0.8$ vs $0.06 \pm 0.8 \mathrm{~kg} / \mathrm{m}^{2} ; \mathrm{p}=0.013$ ). Similarly, the inclusion of eggs in the habitual diet daily, as compared with the exclusion of eggs, significantly reduced visceral fat rating $(-0.4 \pm 1.0$ vs $0.2 \pm 1.1 ; \mathrm{p}=0.016)$. The inclusion of eggs in the habitual diet also reduced waist circumference and percent body fat from baseline (waist circumference: $-0.4 \pm 1.2 \mathrm{~cm}, \mathrm{p}=0.004$; percent body fat -0.7 $\pm 1.8, \mathrm{p}=0.033)$. A complete set of data on the clinical end points is presented in table 2 .

Daily inclusion of eggs in the habitual diet, as compared with egg exclusion, did not improve diet quality. Diet quality, dietary intakes of kilocalories and selected nutrients are presented in table 3 .

\section{DISCUSSION}

Our data suggest that short-term daily inclusion of eggs in the habitual diet of adults with type 2 diabetes was associated with improved anthropometric measures and had no effect on glycemic control and blood pressure. The exclusion of eggs from the habitual diet increased insulin resistance. The inclusion of eggs in the habitual diet did not improve overall diet quality.

In our study, the inclusion of eggs in the habitual diet, as compared with egg exclusion, non-significantly reduced glycemic hemoglobin and had no effects on insulin resistance. The exclusion of eggs from the habitual diet increased insulin resistance. In a previous study by Pearce $e t$ al with type 2 diabetes and impaired glucose tolerance individuals, ${ }^{23}$ daily consumption of eggs for 12 weeks as compared with lean animal protein improved glycemic control and cholesterol levels. In another study by Ratliff $e t a l^{24}$ with apparently healthy men, daily consumption of eggs for breakfast for 1 week, as compared with bagels, reduced plasma glucose, insulin, energy intake, and suppressed ghrelin response. Eggs have a relatively low glycemic index and therefore 
Table 2 Changes in outcome measures

\begin{tabular}{|c|c|c|c|}
\hline Variable & Egg exclusion $(n=34)$ & Egg inclusion $(n=34)$ & p Value \\
\hline \multicolumn{4}{|c|}{ Glycated hemoglobin A1c (\%) } \\
\hline Baseline & $7.3 \pm 0.8$ & $7.5 \pm 1.0$ & \multirow[t]{2}{*}{0.374} \\
\hline 12 weeks & $7.3 \pm 0.8$ & $7.3 \pm 0.8$ & \\
\hline Change & $0.01 \pm 0.5(p=0.948)$ & $-0.24 \pm 0.7(p=0.062)$ & 0.115 \\
\hline \multicolumn{4}{|c|}{ Homeostatic model assessment (IR) } \\
\hline Baseline & $5.9 \pm 3.8$ & $7.5 \pm 6.0$ & \multirow[t]{2}{*}{0.213} \\
\hline 12 weeks & $7.5 \pm 5.1$ & $7.4 \pm 9.1$ & \\
\hline Change & $1.5 \pm 4.1(p=0.047)$ & $0.3 \pm 6.9(p=0.787)$ & 0.420 \\
\hline \multicolumn{4}{|c|}{ Diastolic blood pressure $(\mathrm{mm} \mathrm{Hg})$} \\
\hline Baseline & $74.8 \pm 8.8$ & $75.2 \pm 7.4$ & \multirow[t]{2}{*}{0.859} \\
\hline 12 weeks & $75.3 \pm 7.9$ & $74.7 \pm 8.6$ & \\
\hline Change & $0.9 \pm 9.1(p=0.557)$ & $-0.5 \pm 6.1(p=0.656)$ & 0.460 \\
\hline \multicolumn{4}{|c|}{ Systolic blood pressure $(\mathrm{mm} \mathrm{Hg})$} \\
\hline Baseline & $134.2 \pm 15.0$ & $133.6 \pm 15.2$ & \multirow[t]{2}{*}{0.873} \\
\hline 12 weeks & $132.9 \pm 12.6$ & $130.6 \pm 15.1$ & \\
\hline Change & $-0.8 \pm 13.0(p=0.731)$ & $-3.0 \pm 10.0(p=0.091)$ & 0.438 \\
\hline \multicolumn{4}{|l|}{ Weight (lb) } \\
\hline Baseline & $216.9 \pm 46.5$ & $217.1 \pm 46.1$ & \multirow[t]{2}{*}{0.984} \\
\hline 12 weeks & $218.6 \pm 47.6$ & $214.2 \pm 45.1$ & \\
\hline Change & $0.4 \pm 4.7(p=0.644)$ & $-2.9 \pm 5.0(p=0.002)$ & 0.007 \\
\hline \multicolumn{4}{|c|}{ Waist circumference (cm) } \\
\hline Baseline & $112.0 \pm 13.2$ & $112.0 \pm 13.2$ & \multirow[t]{2}{*}{0.993} \\
\hline 12 weeks & $112.4 \pm 12.9$ & $111.6 \pm 13.0$ & \\
\hline Change & $-0.2 \pm 1.6(p=0.651)$ & $-0.4 \pm 1.2(p=0.004)$ & 0.553 \\
\hline \multicolumn{4}{|c|}{ Body mass index $\left(\mathrm{kg} / \mathrm{m}^{2}\right)$} \\
\hline Baseline & $33.7 \pm 5.9$ & $33.7 \pm 5.7$ & \multirow[t]{2}{*}{0.985} \\
\hline 12 weeks & $34.0 \pm 5.7$ & $33.3 \pm 5.4$ & \\
\hline Change & $0.06 \pm 0.8(p=0.651)$ & $-0.4 \pm 0.8(p=0.004)$ & 0.013 \\
\hline \multicolumn{4}{|l|}{ Body fat (\%) } \\
\hline Baseline & $38.6 \pm 9.9$ & $39.1 \pm 9.3$ & \multirow[t]{2}{*}{0.848} \\
\hline 12 weeks & $39.2 \pm 9.2$ & $38.4 \pm 9.6$ & \\
\hline Change & $0.2 \pm 3.3(p=0.678)$ & $-0.7 \pm 1.8(p=0.033)$ & 0.156 \\
\hline \multicolumn{4}{|c|}{ Visceral fat rating } \\
\hline Baseline & $17.3 \pm 6.7$ & $17.5 \pm 6.4$ & \multirow[t]{2}{*}{0.883} \\
\hline 12 weeks & $17.6 \pm 6.5$ & $17.1 \pm 6.4$ & \\
\hline Change & $0.2 \pm 1.1(p=0.269)$ & $-0.4 \pm 1.0(p=0.021)$ & 0.016 \\
\hline \multicolumn{4}{|l|}{ Water (\%) } \\
\hline Baseline & $43.9 \pm 5.5$ & $43.7 \pm 5.3$ & \multirow[t]{2}{*}{0.885} \\
\hline 12 weeks & $43.6 \pm 5.4$ & $44.1 \pm 5.3$ & \\
\hline Change & $-0.2 \pm 2.0(p=0.603)$ & $0.4 \pm 1.2(p=0.078)$ & 0.179 \\
\hline
\end{tabular}

do not affect blood glucose levels. In addition, eggs are a satiating food and hence can reduce caloric intake, which may consequently help to improve glycemic control. While the detectable difference observed in glycemic control in our study is clinically meaningful, the lack of statistical significance on the effects on glycemic control with the inclusion of eggs in the habitual diet could be due to small sample size, inadequate amount of eggs consumed, and/or inadequate intervention length.

We demonstrated that daily inclusion of eggs in the habitual diet for 12 weeks reduced body weight, waist circumference, visceral fat rating, and percent body fat in adults with type 2 diabetes. Similarly, in a study by
Vander et $a l,{ }^{25}$ the consumption of an egg breakfast for 8 weeks, as compared with bagel, reduced body weight, waist circumference, and percent body fat in overweight adults. However, Katz et $a t^{26}$ showed no effects in body weight with the inclusion of eggs or Egg Beaters in the habitual diet of adults with established coronary artery disease. Eggs are considered a reference food for protein quality, and are considered a satiating food due to their relatively high protein content and low energy density.

The inclusion of eggs in the habitual diet of adults with type 2 diabetes non-significantly reduced systolic blood pressure. In a previous study by Katz et $a l,{ }^{26}$ daily consumption of eggs or Egg Beaters for 6 weeks had no 
Table 3 Change in diet quality, intake of calories and selected nutrients

\begin{tabular}{|c|c|c|c|}
\hline Variable & Egg exclusion $(n=34)$ & Egg inclusion $(n=34)$ & p Value \\
\hline \multicolumn{4}{|c|}{ Diet quality (HEI 2010) } \\
\hline Baseline & $52.9 \pm 11.0$ & $52.9 \pm 11.0$ & \multirow[t]{2}{*}{1.000} \\
\hline 12 weeks & $49.2 \pm 13.6$ & $52.1 \pm 11.3$ & \\
\hline Change & $-3.5 \pm 12.8(p=0.121)$ & $-0.2 \pm 11.3(p=0.925)$ & 0.269 \\
\hline \multicolumn{4}{|c|}{ Total calorie (kcal) } \\
\hline Baseline & $1763.0 \pm 558.6$ & $1763.0 \pm 558.6$ & \multirow[t]{2}{*}{1.000} \\
\hline 12 weeks & $1983.0 \pm 857.5$ & $1878.1 \pm 692.9$ & \\
\hline Change & $253.0 \pm 847.8(p=0.101)$ & $131.9 \pm 512.5(p=0.169)$ & 0.496 \\
\hline \multicolumn{4}{|c|}{ Carbohydrate (kcal) } \\
\hline Baseline & $804.9 \pm 259.6$ & $804.9 \pm 259.6$ & \multirow[t]{2}{*}{1.000} \\
\hline 12 weeks & $864.2 \pm 334.2$ & $805.2 \pm 342.4$ & \\
\hline Change & $59.6 \pm 273.2(p=0.219)$ & $6.0 \pm 282.8(p=0.905)$ & 0.440 \\
\hline \multicolumn{4}{|c|}{ Total fat (kcal) } \\
\hline Baseline & $681.8 \pm 273.8$ & $681.8 \pm 273.8$ & \multirow[t]{2}{*}{1.000} \\
\hline 12 weeks & $693.3 \pm 376.4$ & $800.1 \pm 399.9$ & \\
\hline Change & $35.7 \pm 296.4(p=0.494)$ & $119.6 \pm 320.5(p=0.043)$ & 0.277 \\
\hline \multicolumn{4}{|l|}{ Protein (kcal) } \\
\hline Baseline & $319.9 \pm 103.9$ & $319.9 \pm 103.9$ & \multirow[t]{2}{*}{1.000} \\
\hline 12 weeks & $330.6 \pm 149.3$ & $355.9 \pm 142.6$ & \\
\hline Change & $12.4 \pm 127.5(p=0.579)$ & $39.5 \pm 137.1(p=0.113)$ & 0.413 \\
\hline
\end{tabular}

effects on blood pressure in adults with established coronary artery disease. Eggs produce some peptides that act in a manner similar to ACE inhibitors in lowering blood pressure. ${ }^{27}$ Although the reduction we observed in systolic blood pressure with the inclusion of eggs in the habitual diet was clinically meaningful, we did not see statistical significance. The lack of statistical significance in our study is probably due to the small sample size and/or short duration of intervention.

The inclusion of eggs in the habitual diet of our study participants did not improve their overall diet quality. Better diet quality has been associated with lower mortality, and with reduced incidence of cardiovascular disease and cancer. ${ }^{28}{ }^{29}$ In theory, the inclusion of eggs could improve diet quality by displacing less nutritious food in the habitual diet. On the other hand, the exclusion of eggs from the habitual diet could lead to the introduction of less nutritious foods which could negatively impact diet quality. In our own study, we did not see improvement in diet quality, possibly due to the small sample size or an inadequate amount of eggs consumed.

This study had several limitations. First, the participants were predominantly Caucasians, which limits the ability to generalize our findings. Second, the study had a small sample size. This limitation was overcome to some extent by crossing over the participants to the two different treatment assignments, thereby improving the power of the study. Third, the study relied on self-report by the participants for their dietary records, which can introduce measurement and recall biases. Fourth, the participants were not monitored on a daily basis and were not administered a supervised diet. However, this can also be viewed as a strength of the study because it provides a more realistic scenario and potentially increases external validity. In addition, the variation of the dietary patterns of participants may make it difficult to interpret the findings. Fifth, the Tanita SC-240 analyzer that we used to measure body composition can only be used for individuals with body weight not exceeding $200 \mathrm{~kg}$.

\section{CONCLUSIONS}

Short-term daily inclusion of eggs in the habitual diet of adults with type 2 diabetes led to improved anthropometric measures and had no effect on glycemic control and blood pressure. A larger, long-term, multisite, randomized control trial is warranted to replicate these findings. Mechanistic studies are also warranted to understand the mechanism through which egg consumption exerts these benefits.

\section{Acknowledgements The authors wish to acknowledge the technical assistance of Ms Susan Acheychek.}

Contributors VYN designed the study, was responsible for study implementation oversight, analyzed data, wrote paper, and was responsible for final content. RGA was the project coordinator and wrote paper. HR wrote paper. JAT was the study dietitian and wrote paper. DLK designed research, wrote paper, provided critical review of the manuscript, and was responsible for final content.

Funding Funding for this study has been provided by the Egg Nutrition Center/American Egg Board.

Competing interests None declared.

Ethics approval Griffin Hospital Institutional Review Board.

Provenance and peer review Not commissioned; externally peer reviewed. 
Data sharing statement No additional data are available.

Open Access This is an Open Access article distributed in accordance with the Creative Commons Attribution Non Commercial (CC BY-NC 4.0) license, which permits others to distribute, remix, adapt, build upon this work noncommercially, and license their derivative works on different terms, provided the original work is properly cited and the use is non-commercial. See: http:// creativecommons.org/licenses/by-nc/4.0/

\section{REFERENCES}

1. National Diabetes Statistics Report. 2014. 3/11/2016. http://www.cdc. gov/diabetes/pubs/statsreport14/national-diabetes-report-web.pdf

2. Centers for Disease Control and Prevention. http://www.cdc.gov/ diabetes/basics/prevention.html

3. National Institutes of Health, Digestive and Kidney Diseases. Statistics Related to Overweight and Obesity: The Economic Costs. http://www.niddk.nih.gov/health/nutrit/pubs/statobes.htm\#econ

4. National Institutes of Health, Digestive and Kidney Diseases. https:// www.niddk.nih.gov/health-information/diabetes/types/prediabetesinsulin-resistance

5. Bitzur R, Cohen H, Kamari Y, et al. Triglycerides and HDL Cholesterol Stars or second leads in diabetes? Diabetes Care 2009;32:S373-7.

6. American Diabetes Association, North American Association for the Study of Obesity, American Society for Clinical Nutrition. Weight management using lifestyle. Modification in the prevention and management of type 2 diabetes: rationale and strategies. Clinical Diabetes 2005;23:130-6.

7. Knowler WC, Barrett-Connor E, Fowler SE, et al., Diabetes Prevention Program Research Group. Reduction in the incidence of type 2 diabetes with lifestyle intervention or metformin. N Engl J Med 2002;346:393-403.

8. http://www.thecommunityguide.org/diabetes/combineddietandpa.htm/

9. Pronk NP. Structured diet and physical activity programmes provide strong evidence of effectiveness for type 2 diabetes prevention and improvement of cardiometabolic health. Evid Based Med 2016;21:18.

10. Ackermann RT. Diabetes prevention at the tipping point: aligning clinical and public health recommendations. Ann Intern Med 2015:163:475-6.

11. Balk EM, Earley A, Raman G, et al. Combined diet and physical activity promotion programs to prevent type 2 diabetes among persons at increased risk: a systematic review for the Community Preventive Services Task Force. Ann Intern Med 2015;163:437-51.

12. Knowler WC, Barrett-Connor E, Fowler SE, et al., Diabetes Prevention Program Research Group. 10-year follow-up of diabetes incidence and weight loss in the Diabetes Prevention Program Outcomes Study. Lancet 2009;374:1677-86.

13. Tuomilehto J, Lindstrom J, Eriksson JG, et al. Finnish Diabetes Prevention Study Group,, Prevention of type 2 diabetes mellitus by changes in lifestyle among subjects with impaired glucose tolerance. N Engl J Med 2001;344:1343-50.
14. Shin JY, Xun $P$, Nakamura $Y$, et al. Egg consumption in relation to risk of cardiovascular disease and diabetes: a systematic review and meta-analysis. Am J Clin Nutr 2013;98:146-59.

15. Djoussé L, Khawaja OA, Gaziano JM. Egg consumption and risk of type 2 diabetes: a meta-analysis of prospective studies. Am J Clin Nutr 2016;103:474-80.

16. Tamez M, Virtanen JK, Lajous M. Egg consumption and risk of incident type 2 diabetes: a dose-response meta-analysis of prospective cohort studies. Br J Nutr 2016;115:2212-18.

17. Deurenberg P, Andreoli A, Borg P, et al. The validity of predicted body fat percentage from body mass index and from impedance in samples of five European populations. Eur J Clin Nutr 2001;55:973-9.

18. Barreira TV, Staiano AE, Katzmarzyk PT. Validity assessment of a portable bioimpedance scale to estimate body fat percentage in white and African American children and adolescents. Pediatr Obes 2013;8:e29-32.

19. Johnson KE, Naccarato IA, Corder MA, et al. Validation of three body composition techniques with a comparison of ultrasound abdominal fat depths against an octopolar bioelectrical impedance device. Int J Exerc Sci 2012;5:205-13.

20. Yamakage $\mathrm{H}$, Ito $\mathrm{R}$, Tochiya $\mathrm{M}$, et al. The utility of dual bioelectrical impedance analysis in detecting intra-abdominal fat area in obese patients during weight reduction therapy in comparison with waist circumference and abdominal CT. Endocr J 2014;61:807-19.

21. Oh JY, Sung YA, Lee HJ. The visceral adiposity index as a predictor of insulin resistance in young women with polycystic ovary syndrome. Obesity (Silver Spring) 2013;21:1690-4.

22. Jenkins DJ, Kendall CW, McKeown-Essyn G, et al. Effect of a low-glycemic index or a high-cereal fiber diet on type 2 diabetes: a randomized trial. JAMA 2008;300:2742-53.

23. Pearce KL, Clifton PM, Noakes M. Egg consumption as part of an energy-restricted high-protein diet improves blood lipid and blood glucose profiles in individuals with type 2 diabetes. $\mathrm{Br} J$ Nutr 2011;105:584-92.

24. Ratliff J, Leite JO, de Ogburn R, et al. Consuming eggs for breakfast influences plasma glucose and ghrelin, while reducing energy intake during the next 24 hours in adult men. Res 2010;30:96-103.

25. Vander Wal JS, Gupta A, Khosla P, et al. Egg breakfast enhances weight loss. Int J Obes (Lond) 2008;32:1545-51.

26. Katz DL, Gnanaraj J, Treu JA, et al. Effects of egg ingestion on endothelial function in adults with coronary artery disease: a randomized, controlled, crossover trial. Am Heart J 2015;169:162-9.

27. Majumder K, Wu J. Angiotensin I converting enzyme inhibitory peptides from simulated in vitro gastrointestinal digestion of cooked eggs. J Agric Food Chem 2009;57:471-7.

28. Harmon BE, Boushey CJ, Shvetsov YB, et al. Associations of key diet-quality indexes with mortality in the Multiethnic Cohort: the Dietary Patterns Methods Project. Am J Clin Nutr 2015;101:587-97.

29. Reedy J, Krebs-Smith SM, Miller PE, et al. Higher diet quality is associated with decreased risk of all-cause, cardiovascular disease, and cancer mortality among older adults. J Nutr 2014;144:881-9. 